\title{
Inverse edge effect on nest predation in a Kenyan forest fragment: an experimental case study
}

\author{
TOON SPANHOVE, VALÉRIE LEHOUCK and LUC LENS
}

\begin{abstract}
Summary
Fragmentation of continuous habitat blocks into small, isolated patches may cause gradual replacement of habitat specialists by generalists and edge-dwelling species, thereby altering trophic interactions within communities. When fragmentation progressively increases the edgeto-interior ratio of forest remnants, forest birds are typically exposed to higher levels of nest predation, especially so near forest edges. However, the strength and direction of this 'edge effect on nest predation' may vary with predator communities, which in turn can be affected by habitat type, landscape structure and geographical location. We studied avian nest predation in two isolated forest fragments in the Taita Hills of southeast Kenya, where small mammals, rather than birds, dominate predator communities. The use of artificial ground nests allowed us to reduce variation in laying date and microhabitat use, which are known to affect predation on natural nest in the study area. Predation rates did not increase near the forest boundary, but instead, were higher in the forest interior of one of the fragments. Such inverse edge effects may be caused by forest-dependent small mammals or snakes that can remove bird eggs. Although inverse edge effects may be more common in East African tropical forests than previously thought, and should therefore be taken into account when drafting conservation plans, the underlying mechanisms remain unclear. Further study of the population dynamics of small mammals and snakes, and their relative impact on nest predation in fragmented habitats, is therefore required.
\end{abstract}

\section{Introduction}

Loss, deterioration and fragmentation of continuous forest blocks into small, isolated remnants are widely considered as important causes of the current extinction wave in tropical ecosystems (Pimm and Raven 2000, Brooks et al. 2002, Laurence et al. 2002). Through cascade effects, the loss or decline of single species may adversely affect the viability of a suite of other species, both within and between trophic levels (Laurance 2005). For example, local extinction of a single top predator may release the predation pressure on secondary predators, which can then affect the population dynamics of a suite of smaller species (Crooks and Soule 1999). At the same time, ecosystems may also be threatened by the introduction or sudden increase in certain species. The introduction of small mammals (e.g. rats, cats) onto oceanic islands by human settlers, for instance, quickly resulted in the (near) extinction of many ground-breeding bird species (Imber et al. 2000, Jones et al. 2005), which may have offered crucial ecological functions such as seed dispersal and nutrient deposition (Sekercioglu 2006).

When fragmentation progressively increases the edge-to-interior ratio of forest remnants, bird nests are typically exposed to higher predation pressures. Shortly after the destruction of suitable habitat, mobile organisms will take refuge in remaining patches (Goss-Custard et al. 1995, Hagan et al. 1996). In these terrestrial islands, densities of both breeding birds and their main predators 
will temporarily increase, which may result in elevated levels of nest predation. But even after bird and predator density have reached an ecological equilibrium, predation rates may remain high in small patches or at forest-field ecotones compared to forest interior. First, the structural diversity of edges provides singing posts, suitable nesting cover and feeding sites for a wide range of bird species, and often results in high nest densities, which may attract nest predators (Gates and Gysel 1978, Weldon and Haddad 2005). Second, both forest and fields may act as a barrier for open field and forest predators respectively, hence, forest-field ecotones may act as 'travellanes' with elevated predator activities (Bider 1968, Ferguson 2000, but see Larivière 2003). Third, species that are associated with habitat edges or the surrounding landscape matrix may invade forest boundaries from the surrounding landscape. This may not only result in increased predation near forest edges, but may additionally increase the competition between forest specialist birds with matrix-dwelling species invading the forest (Janzen 1983, Ness and Morin 2008).

Despite the common belief that rates of avian nest predation increase near habitat edges, more than half of 54 case studies reviewed by Lahti (2001) failed to support a negative relationship between nest predation and distance from the forest edge. In some of these studies, putative edge effects may have been concealed due to inappropriate spatial or temporal scales of the study (Paton 1994, Stephens et al. 2003), insufficient statistical power (Lewis 2004), or the exclusive use of artificial nests which may mask patterns of natural nest predation (Haskell 1995a,b, Zanette 2002, Burke et al. 2004). However, well-designed studies also either failed to show significant edge effects (e.g. Hanski et al. 1996, Tewksbury et al. 1998, Morse and Robinson 1999) or revealed heterogeneity in the strength or direction of the reported relationships (Hartley and Hunter 1998, Lahti 2001, Chalfoun et al. 2002, Stephens et al. 2003). Such heterogeneity may indicate that nesting species differ in their ability to cope with habitat change (e.g. through nest concealment or parental care; King et al. 1999, Martin et al. 2000, Yasue and Dearden 2006, but see Fontaine et al. 2007), or alternatively, that nest predators differ in their responses to habitat change (Chalfoun et al. 2002). Some predator species may be typically associated with edge and matrix habitat, and their numbers can be expected to increase when both edge-to-area and matrix-to-habitat ratios increase under increasing habitat fragmentation (Gates and Gysel 1978, Marzluff and Ewing 2001). In contrast, predator species restricted to pristine environments may be adversely affected by habitat degradation and fragmentation. Both in temperate (Andrén 1992, Nour et al. 1993, Hannon and Cotterill 1998) and tropical forest communities (Gibbs 1991, Telleria and Diaz 1995), bird nests in the interior of forests are mainly predated by small mammals, while avian predators seem to be concentrated at forest edges. As a consequence, the strength and direction of edge effects on nest predation may be affected by the composition of predator communities, which in turn may vary with habitat type, landscape structure and geographic location (Tewksbury et al. 1998, Chalfoun et al. 2002).

In East African forests, avian nest predation is mainly attributed to (small) mammals, rather than to birds (Carlson and Hartman 2001, Githiru et al. 2005, Hanson et al. 2007). In the absence of important avian nest predators typically associated with edges, rates of nest predation can either be expected to show no edge effect or an inverse one, i.e. stronger predation with increasing distances from forest edges. We here test this hypothesis with the use of artificial ground nests baited with plasticine eggs. While the use of artificial nests is strongly debated (Zanette 2002, Burke et al. 2004, Robinson et al. 2005) because predators may be differentially attracted to natural and artificial nests (Montgomerie and Weatherhead 1988, Willebrand and Marcström 1988, Martin et al. 2000) or because quail or chicken eggs used in artificial nest experiments are too large to handle for small predators (Haskell $1995 \mathrm{a}, \mathrm{b}$, Hanson et al. 2007), it also offers important advantages. First, confounding effects of laying date and microhabitat use, both of which were shown to affect predation rates on natural nests in our study area (Spanhove et al. 2009), can be accounted for. Second, experiments with artificial nests can circumvent the problem of inadequate statistical power resulting from small samples of natural nests. The use of plasticine eggs has the additional advantage to reveal predator identity without intensive nest searching or the use of expensive optical equipment. However, results should be interpreted with caution as 
nest predation by small mammals may be overestimated (Pärt and Wretenberg 2002). Based on these considerations and the fact that observed depredation on natural White-starred Robins Pogonocichla stellata nests (Spanhove et al. 2009) corresponded well with that on a set of artificial nests in the same study area (Githiru et al. 2005), we here address the question if, and to what extent, spatial variation in artificial nest predation rates supports the presence of an inverse edge effect for a ground-nesting forest species.

\section{Material and Methods}

The Taita Hills of South-East Kenya $\left(3^{\circ} 20^{\prime} \mathrm{S} 38^{\circ} 15^{\prime} \mathrm{E}\right)$ form the northernmost extension of the ancient Eastern Arc Mountains and are part of the Eastern Afromontane biodiversity hotspot (Mittermeier et al. 2005, Burgess et al. 2007). Within the study area, few fragments of (degraded) indigenous cloud forest persist in a landscape which is dominated by dry shrubland and small subsistence farmland (Beentje 1988). Table 1 lists all putative predators of bird eggs and nestlings in the Taita forest remnants, based on 12 years of mist-net captures (1996-2008), five years of behavioural observations (2003-2008) and literature data (Beentje 1988, Malonza 2001, Oguge 2001, R. Odhiambo unpubl. data, K. Malonza and G. J. Measey unpubl. data). We studied artificial nest predation rates in the two largest forest fragments located within the most heavily fragmented mountain isolate (Dabida) of the Taita Hills, where less than $2 \%$ of indigenous forest cover remains (Figure 1 ): Ngangao ( 133 ha indigenous forest/161 ha when

Table 1. Putative nest predators in the indigenous forest fragments of the Taita Hills, south-east Kenya. For avian predators, numbers captured since 1996 are given between brackets (total number of captures was 20,701).

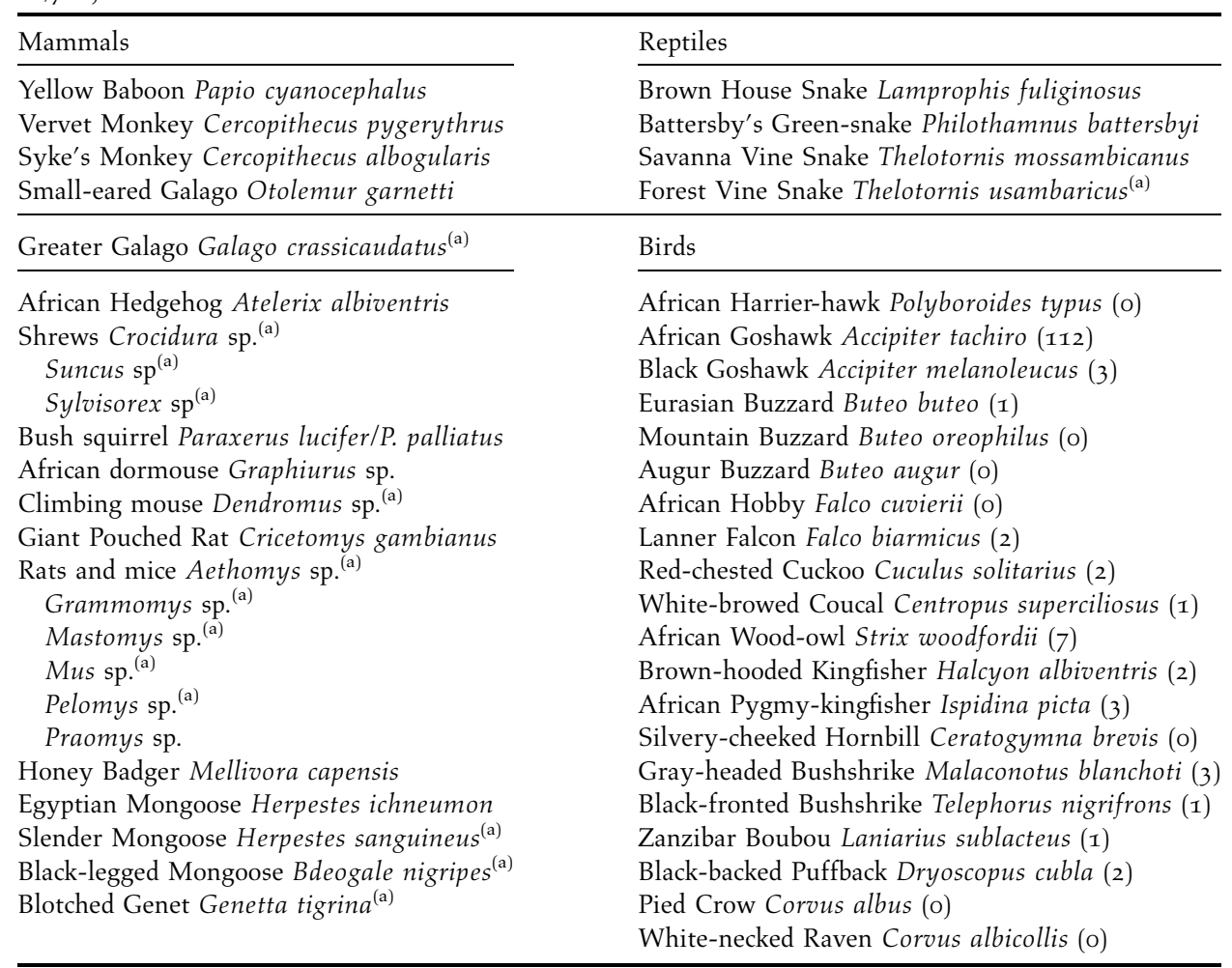

${ }^{(a)}$ presence in Taita Hills inferred from literature only (see text). 


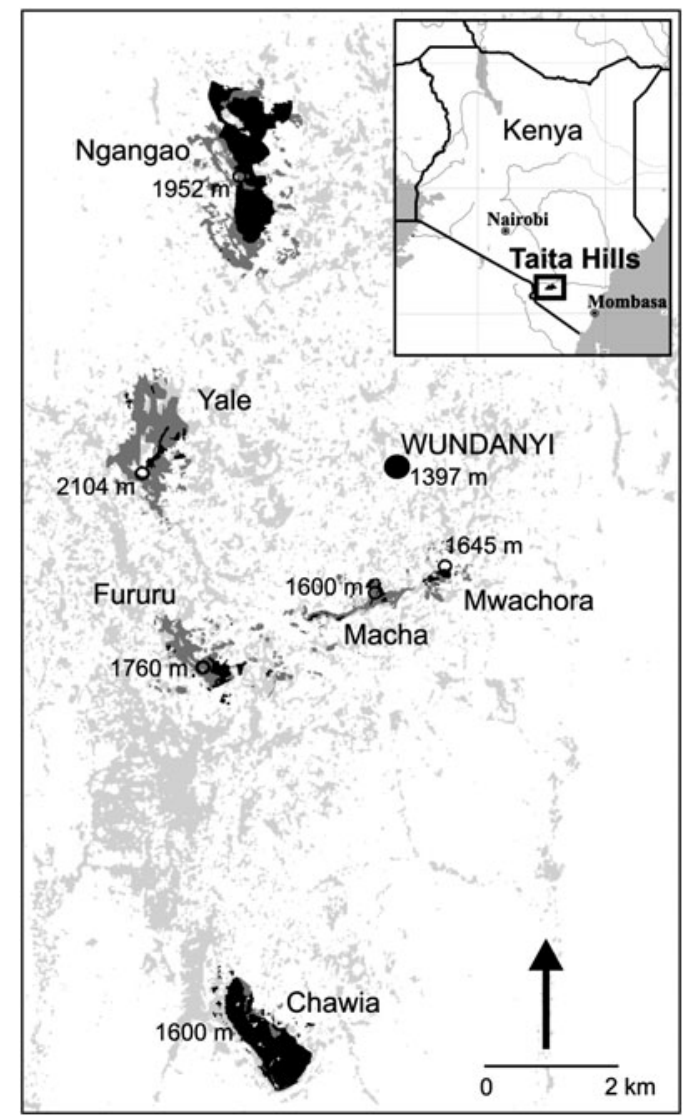

Figure 1. Map of the Taita study area above the main forest-shrubland boundary (alt. 1,200 m). Black: indigenous forest fragments; dark grey: exotic plantations; light grey: woodland and isolated tree patches; white: settlements and small-holder cultivation plots (mainly maize, cabbages, beans and bananas). Based on aerial photographs (P. Pellikka, unpublished data).

including exotic plantations surrounding the indigenous forest) and Chawia (9o ha/95ha) (P. Pellikka unpubl. data).

Between 18 January and 9 February 2007, i.e. late breeding season, a total of 14 (Ngangao) and 15 (Chawia) transects were established, each measuring $170 \mathrm{~m}$, located perpendicularly to the forest edge and at least $100 \mathrm{~m}$ apart. Each transect started at a distinct edge between indigenous forest and agricultural land ('cantilevered' type sensu Murcia 1995), and ran through homogenous indigenous forest, i.e. avoiding exotic plantations and large tree-fall gaps. A total of 470 dome-shaped finch-nests ('Birdie' Art ${ }^{\circ}$ 100497, Flamingo, Herentals, Belgium) resembling those of ground nesting White-starred Robins and Yellow-throated Woodland-warblers Phylloscopus ruficapillus, were placed at ground level and concealed with leaves and branches in locations similar to those of natural nests. Each nest was baited with two plasticine eggs that were similar in size and shape to White-starred Robin eggs. To reduce the level of autocorrelation, nests were placed at $30 \mathrm{~m}$ intervals along each transect and were shifted twice (after six days of exposure) to cover all $10 \mathrm{~m}$ intervals in between. To reduce human scent, latex gloves were used during all manipulations of nests and eggs. Prior to formal hypothesis testing, we verified whether predation rates on nests at $10 \mathrm{~m}$ distance were statistically independent by comparing observed versus expected nests 
with 0,1 and 2 predated neighbouring nests $\left(G_{2}=0.29, P=0.86\right.$; expected numbers based on average predation rate per transect) (details in Hannon and Cotterill 1998). Within a radius of $5 \mathrm{~m}$ around each nest, we scored the presence of exotic trees and the structure of understorey and canopy (canopy: 'open' $(<50 \%)$ or 'dense' $(>50 \%)$ cover above $5 \mathrm{~m}$; 'gap' if a gap of at least $10 \mathrm{~m}^{2}$ was present in this layer; understorey: 'open' $(<25 \%)$ or 'dense' $(>25 \%)$ cover lower than $1 \mathrm{~m})$. The canopy was more open, the understory was denser and exotic trees were more abundant around artificial nests closer to the fragment edges (General Linear Models, all $P<0.05)$. After six days of exposure, each nest was checked for signs of predation. If tooth marks were present, eggs were collected and imprints were compared with mammalian skulls of species known to occur in the Taita Hills at the National Museums of Kenya (Nairobi, Kenya) and the Royal Museum of Central Africa (Tervuren, Belgium).

Predation rates were analysed with Generalized Linear Mixed Models in SAS v. 9.1.3 (PROC GLIMMIX, SAS Institute 2002-2003). Predation ( 1 or o after six days of exposure) was modelled as binomial distributed dependent variable; distance to the forest edge, fragment and/or habitat structure as fixed effects, and transect as random effect. Since complex models with random effects cannot reliably be compared with information criteria based on pseudo-likelihoods (SAS Institute 2008), we applied a classic stepwise forward procedure (critical $P$-value 0.05) for model selection. In models with random effects, denominator degrees of freedom were computed following Kenward and Roger (1997). In all analyses, the square root of the distance between the nest and the forest edge was used to account for disproportional changes in predation and environmental parameters closer to the edges (Paton 1994, Batáry and Báldi 2004). In a simplified model without random effects, this measure proved a much better predictor than untransformed distances based on a small-sample Akaike Information Criterion (Hurvich and Tsai 1989, Burnham and Anderson 2002; $\triangle \mathrm{AIC}_{\mathrm{c}}=8.6$ ).

\section{Results}

Avian nest predators were only rarely encountered in the Taita forests. Of a total of 20,701 birds trapped with mist-nests between 1996 and 2008, only 140 individuals (0.7\%) were considered as potential nest predators (Table 1 ). Other potential avian predators such as African Harrier-hawk Polyboroides typus and Silvery-cheeked Hornbill Ceratogymna brevis were regularly observed in the intervening landscape matrix or forest canopy, but never in the forest understorey.

A total of 383 nests (81.5\%) were predated after six days' exposure trials. In Chawia, predation rates were significantly higher in the forest interior than near the forest edge $(t=-4.69$, $\left.d_{t}=466, P<0.001\right)$. However, no such trend was apparent in Ngangao $\left(t=-0.38, d_{t}=466\right.$, $P=0.70$; Figure 2). In both fragments, predation increased with increasing density of canopy $\left(F_{2,466}=3.55, P=0.029\right)$ and understory vegetation $\left(F_{1,467}=8.52, P=0.0037\right)$. When applying a forward selection procedure, distance to the forest edge remained significant when accounting for effects of vegetation structure (Figure 2 and Table 2 ).

In 242 predation events $(63 \%)$, eggs were removed from intact nests, while in 70 others $(18.5 \%)$ nests were destroyed, most likely by larger predators such as monkeys, galagos, carnivores, squirrels, pouch rats or hornbills. In three of these nests, eggs showed imprints of the Giant Pouched Rat Cricetomys gambianus. As judged from tooth marks on eggs in intact nests, small rodents and shrews accounted for predation of the remaining 71 nests (18.5\%). In 57 of these, tooth marks could be assigned to mice (e.g. Praomys sp., Mus sp., Mastomys sp. or Grammomys sp.), while seven clutches showed imprints of a shrew (probably Crocidura olivieri) and four clutches showed imprints of a dormouse (probably Graphiurus microtis).

The proportion of nests assigned to either type of predation significantly different between both fragments $\left(\chi_{2}^{2}=49.1, P<0.0001\right.$, Figure 3$)$. In Chawia, eggs were more often removed from intact nests, while in Ngangao, nests were either destroyed or showed eggs with tooth marks more often (Figure 3). The proportion of nests that were either destroyed or contained eggs with imprints, did not vary in relation to vegetation structure or distance to the edge (Table 2). 


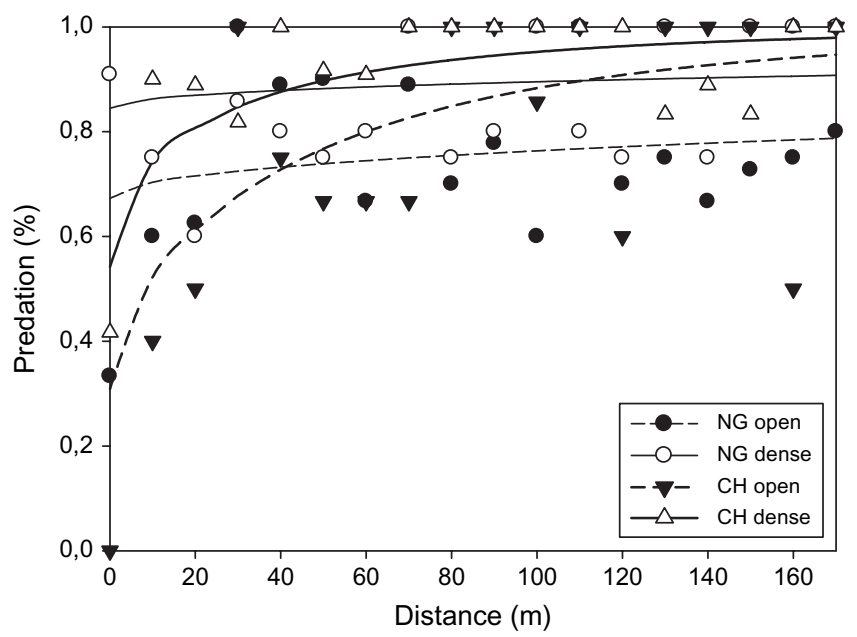

Figure 2. Inverse edge effect on artificial nest predation in Chawia $(\mathrm{CH})$, but not in Ngangao (NG). Predation was higher in dense understorey (dense) than in open understorey (open) in both fragments. Lines depict model estimates, symbols depict observed predation rates.

In contrast, the proportion of nests with missing eggs increased with density of the understorey and distance to the forest edge in Chawia, but not in Ngangao (Table 2, Figure 3).

\section{Discussion}

In many regions, avian nests are believed to be prone to elevated predation levels near forest edges compared to the interior of pristine forests (Hartley and Hunter 1998, Lahti 2001, Chalfoun et al. 2002, Stephens et al. 2003). Such edge effect on nest predation was not supported by our artificial nest experiment in two indigenous forest fragments. Instead, a significant inverse edge-effect, i.e. higher predation rates in the forest interior, was evident in Chawia, but not in Ngangao. Both fragments only lie $11 \mathrm{~km}$ apart and are similar in general appearance, although fragment Chawia has a more dense herb layer and lacks typical highland canopy species such as Podocarpus spp. and Ocotea spp, possibly due to its lower elevation. Despite being smaller, Chawia (9o ha) has relative more forest interior, but is more isolated from other forest patches than Ngangao (133 ha). Both fragments are surrounded by densely populated subsistence

Table 2. Tests of fixed and random effects on predation of 470 artificial nests. Results from generalized linear mixed models are shown for all predation events combined (pooled) and for each predation type separately (eggs missing; nest destroyed; tooth marks).

\begin{tabular}{|c|c|c|c|c|}
\hline & Pooled & Eggs missing & Nest destroyed & Tooth marks \\
\hline \multicolumn{5}{|c|}{ Cov. Parameter $( \pm S E)$} \\
\hline Transect & $0.41( \pm 0.21)$ & $0.41( \pm 0.21)$ & $0.26( \pm 0.24)$ & $0.27( \pm 0.18)$ \\
\hline \multicolumn{5}{|l|}{ Fixed Effect } \\
\hline Fragment & $\mathrm{F}_{1,215}=5.45^{*}$ & $\mathrm{~F}_{1,264}=0.00^{\text {n.s. }}$ & $\mathrm{F}_{1,30}=21.12^{* * *}$ & $\mathrm{~F}_{1,25}=25.00^{* * *}$ \\
\hline Distance & $\mathrm{F}_{1,465}=17.57^{* * *}$ & $\mathrm{~F}_{1,465}=13.90^{* * *}$ & $\mathrm{~F}_{1,467}=1.16^{\text {n.s. (a) }}$ & $\mathrm{F}_{1,28}=3.87^{\text {n.s. (a) }}$ \\
\hline Understoryy & $\mathrm{F}_{1,465}=9.25^{* *}$ & $\mathrm{~F}_{1,465}=4.85^{*}$ & $\mathrm{~F}_{1,467}=0.04^{\text {n.s. (a) }}$ & $\mathrm{F}_{1,372}=1.10^{\text {n.s. (a) }}$ \\
\hline Canopy & $\mathrm{F}_{2,463}=0.87^{\text {n.s. (a) }}$ & $\mathrm{F}_{2,463}=0.73^{\text {n.s. (a) }}$ & $\mathrm{F}_{2,466}=0.38^{\text {n.s. (a) }}$ & $\mathrm{F}_{2,466}=0.92^{\text {n.s. (a) }}$ \\
\hline Fragm. ${ }^{*}$ Dist. & $\mathrm{F}_{1,465}=9.55^{* *}$ & $\mathrm{~F}_{1,465}=6.57^{*}$ & - & - \\
\hline
\end{tabular}

(a) non-significant terms excluded from the final model.

n.s. $P>0.05 ;^{*}: P<0.05 ;^{* *}: P<0.01 ;{ }^{* * *}: P<0.001$. 

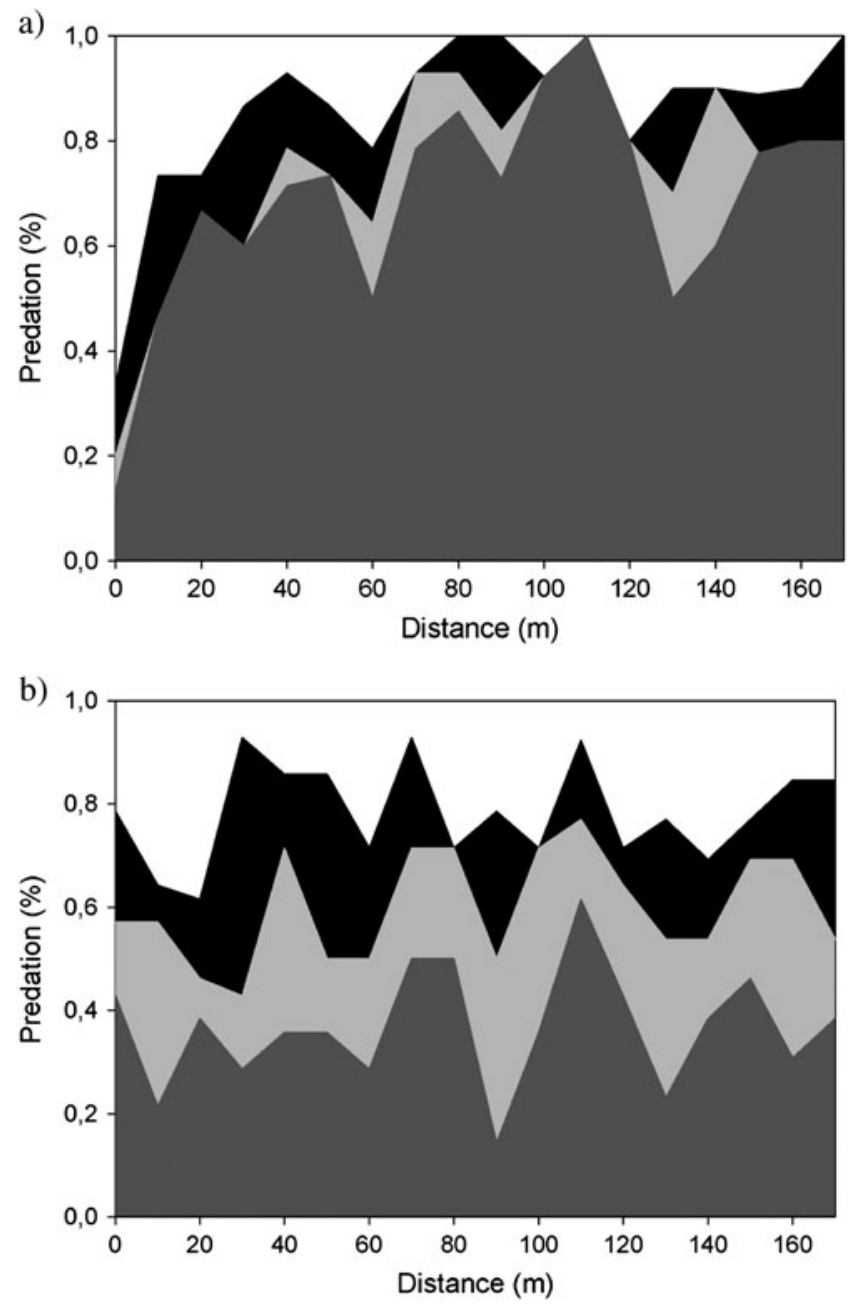

Figure 3. Type of predation on 470 artificial nests in (a) Chawia and (b) Ngangao. Dark grey: intact nest with eggs missing; light grey: nest removed or destroyed; black: intact nest with eggs with tooth marks.

farmlands, although levels of human disturbance (mainly related to firewood collection) and densities of small rodents are higher in fragment Chawia (Oguge 2001, R. Odhiambo unpubl. data). While these, and probably other differences between Chawia and Ngangao may have contributed to the variation in edge effect on nest predation, lack of replicate forest fragments prevents us from drawing solid conclusions on the effects of fragment size, isolation and/or vegetation structure separately. Moreover, an earlier study on natural White-starred Robin nests revealed an inverse edge effect on nest predation in Ngangao as well (Spanhove et al. 2009).

Heterogeneous conclusions drawn from studies on natural and artificial nests have fuelled criticism of the use of the latter in ecological research (Willebrand and Marcström 1988, Haskell 1995a,b, Zanette 2002, Burke et al. 2004). In our study area, artificial nests were more heavily predated than natural ones (Spanhove et al. 2009), even when accounting for effects of laying date. While such a difference may be due to differential predator attraction to artificial and natural nests, it may also reflect shifts in predator composition during the course of 
a breeding season, or low statistical power due to small samples of natural nests. While absolute predation rates differed between artificial and natural nests, relative predation patterns on these two nest types were largely comparable. First, the distribution of predation events across three major types (nest destroyed, eggs missing, tooth marks) did not differ between 470 artificial nests (this study) and 51 natural ones (T. Spanhove unpubl. data; $\chi_{2}^{2}=1.44, P=0.44$ ). Second, for both nest types, predation rates were higher in Chawia. Third, both nest types documented an inverse edge effect, a pattern rarely documented in other regions (Hartley and Hunter 1998, Lahti 2001, Stephens et al. 2003).

The lack of positive edge effects in the Taita Hills (this study, Githiru et al. 2005, Spanhove et al. 2009) and other East African forests (Carlson and Hartman 2001, Maina and Jackson 2003, Hanson et al. 2007) may be related to the absence of avian predators that are closely associated with agricultural fields and forest edges. In regions where avian predators dominate the nest predator community, predation levels are often higher at forest edges (Nearctic: Hannon and Cotterill 1998, Tewksbury et al. 2006; Palearctic: Nour et al. 1993, Mazgajski and Rejt 2005; Neotropic: Gibbs 1991, Telleria and Diaz, 1995; Indomalayan: Posa et al. 2007, but see PangauAdam et al. 2006; Australasian: Hausmann et al. 2005). Although the absence of avian predators may result in a lack of positive edge effects, it cannot explain the high predation levels in the forest interior. Such inverse edge effect may well be attributed to other predator species. However, the specific identity of nest predators cannot reliably be inferred from the remains of nests and eggs, especially when eggs are partly or completely removed from the nests (Larivière 1999). As eggs were removed from the majority of predated nests in this study, inferences on (shifts in) predator communities should be interpreted with caution. When combining all available evidence, however, larger predators such as monkeys and pouch rats can cautiously be ruled out as egg removers, since they would likely damage the small and fragile nest openings, while avian nest predators can be ruled out based on their documented rarity in the Taita forests. Eggs are commonly removed by snakes (Robinson and Robinson 2001, Pärt and Wretenberg 2002, Weatherhead and Blouin-Demers 2004), although these were rarely recorded in the study area (Malonza 2001). In contrast, small mammals such as mice and shrews, which can also remove entire clutches or consume them on the scene (Larivière 1999) are abundant, particularly so in forest fragment Chawia (Oguge 2001, R. Odhiambo unpubl. data). Although small mammals are most likely responsible for the majority of predation events on plasticine eggs, their role in natural nest predation remains vague (Pärt and Wretenberg 2002).

Mortality due to nest predation is often regarded as a major driver of the population dynamics of small forest birds. For instance, high levels of nest predation in Chawia may underlie the poor recruitment, skewed sex ratios and lack of floaters in this fragment (Githiru and Lens 2006, Githiru et al. 2006), despite being the third largest fragment in the Taita Hills. To improve future population viability prospects for small forest birds, conservation plans need to take into account the processes underlying nest predation. For instance, if high predation rates would mainly reflect high rodent densities, (re)introduction and conservation of top predators may relieve forest birds from unnaturally high predation pressure (Crooks and Soulé 1999, Maina and Jackson 2003). Alternatively, if higher predation rates would mainly reflect better thermal conditions for snakes, e.g. due to elevational and structural properties of the forest fragments (Malonza 2001), projected climate changes may reinforce these effects, independently of local habitat restoration programmes. Effective conservation actions therefore remain in need of small-scale, high-resolution studies, such as this one, to better understand the ecological processes underlying spatio-temporal variation in nest predation.

\section{Acknowledgements}

We are grateful to the Kenyan government for approving this research project under MOEST Ref. $\mathrm{N}^{\circ} 13 / 001 / 33 \mathrm{C} 294 / 2$. The staff of the Mammalogy and Osteology Departments of the National Museums of Kenya and the Royal Museum for Central Africa granted access to their 
collections. S. Sokol assisted with fieldwork, K. Geurts with identification of the tooth marks, and F. Hendrickx with statistical analysis. R. O. Odhiambo, K. Malonza and G. J. Measey provided unpublished information on the occurrence of small mammals and reptiles in the Taita Hills; P. Pellikka kindly supplied a map of the study area. Two anonymous reviewers provided helpful comments on earlier versions of the manuscript. This study was supported by projects G.0210.04 and G.0055.08 of Research Foundation - Flanders (FWO), the Science faculty of Ghent University, and VLIR-UOS. TS and VL are research assistants of FWO.

\section{References}

Andrén, H. (1992) Corvid density and nest predation in relation to forest fragmentation - a landscape perspective. Ecology 73 : 794-804.

Batáry, P. and Báldi, A. (2004) Evidence of an edge effect on avian nest success. Conserv. Biol. 18: 389-400.

Beentje, H. J. (1988) An ecological and floristic study of the forests of the Taita Hills, Kenya. Utafiti 1: 23-66.

Bider, J. R. (1968) Animal activity in uncontrolled terrestrial communities as determined by a sand transect technique. Ecol. Monogr. 38: 269-308.

Brooks, T. M., Mittermeier, R. A., Mittermeier, C. G., Da Fonseca, G. A. B., Rylands, A. B., Konstant, W. R., Flick, P., Pilgrim, J., Oldfield, S., Magin, G. and Hilton-Taylor, C. (2002) Habitat loss and extinction in the hotspots of biodiversity. Conserv. Biol. 16: 909-923.

Burgess, N. D., Butynski, T. M., Cordeiro, N. J., Doggart, N. H., Fjeldså, J., Howell, K. M., Kilahama, F. B., Loader, S. P., Lovett, J. C., Mbilinyi, B., Menegon, M., Moyer, D. C., Nashanda, E., Perkin, A., Rovero, F., Stanley, W. T. and Stuart, S. N. (2007) The biological importance of the Eastern Arc Mountains of Tanzania and Kenya. Biol. Conserv. 134: 209-231.

Burke, D. M., Eliliott, K., Moore, L., Dunford, W., Nol, E., Phillips, J., Holmes, S. and Freemark, K. (2004) Patterns of nest predation on artificial and natural nests in forests. Conserv. Biol. 18: 381-388.

Burnham, K. P. and Anderson, D. R. (2002) Model selection and multimodel inference: a practical information-theoretic approach. $2^{\text {nd }}$ edition. New York: Springer.

Carlson, A. and Hartman, G. (2001) Tropical forest fragmentation and nest predation - an experimental study in an Eastern Arc montane forest, Tanzania. Biodivers. Conserv. 10: 1077-1085.

Chalfoun, A. D., Thompson, F. R. and Ratnaswamy, M. J. (2002) Nest predators and fragmentation: a review and meta-analysis. Conserv. Biol. 16: 306-318.

Crooks, K. R. and Soule, M. E. (1999) Mesopredator release and avifaunal extinctions in a fragmented system. Nature 400: 563566.

Ferguson, S. H. (2000) Predator size and distance to edge: is bigger better? Can. J. Zool. 78: 713-720.

Fontaine, J. J., Martel, M., Markland, H. A., Niklison, A. A., Decker, K. L. and Martin, T. E. (2007) Testing ecological and behavioral correlates of nest predation. Oikos 116: $1887-1894$.

Gates, J. E. and Gysel, L. W. (1978) Avian nest dispersion and fledging success in fieldforest ecotones. Ecology 59: 871-883.

Gibbs, J. P. (1991) Avian nest predation in tropical wet forest - an experimental study. Oikos 60: 155-161.

Githiru, M. and Lens, L. (2006) Demography of an Afrotropical passerine in a highly fragmented landscape. Anim. Conserv. 9: 21-27.

Githiru, M., Lens, L. and Cresswell, W. (2005) Nest predation in a fragmented afrotropical forest: evidence from natural and artificial nests. Biol. Conserv. 123: 189-196.

Githiru, M., Lens, L., Bennun, L. A. and Perrins, C. (2006) Experimental evidence of 'floaters' in two isolated populations of an Afrotropical forest bird. Ostrich 77: 28-35.

Goss-Custard, J. D., Caldow, R. W. G., Clarke, R. T., Durell, S. E. A. Le V. Dit, Urfi, J. and West, A. D. (1995) Consequences of habitat 
loss and change to populations of wintering migratory birds: predicting the local and global effects from studies of individuals. Ibis 137: S56-S66.

Hagan, J. M., Vander Haegen, M. and McKinley, P. S. (1996) The early development of forest fragmentation effects on birds. Conserv. Biol. 10: 188-202.

Hannon, S. J. and Cotterill, S. E. (1998) Nest predation in aspen woodlots in an agricultural area in Alberta: the enemy from within. Auk 115: 16-25.

Hanski, I. K., Fenske, T. J. and Niemi, G. J. (1996) Lack of edge effect in nesting success of breeding birds in managed forest landscapes. Auk 113: 578-585.

Hanson, T. R., Newmark, W. D. and Stanley, W. T. (2007) Forest fragmentation and predation on artificial nests in the Usambara mountains, Tanzania. Afr. J. Ecol. 45: 499-507.

Hartley, M. J. and Hunter, M. L. (1998) A meta-analysis of forest cover, edge effects, and artificial nest predation rates. Conserv. Biol. 12: 465-469.

Haskell, D. G. (1995a) Forest fragmentation and nest predation: are experiments with Japanese quail eggs misleading? Auk 112: 767-770.

Haskell, D. G. (1995b) A reevaluation of the effects of forest fragmentation on rates of bird-nest predation. Conserv. Biol. 9: 13161318.

Hausmann, F., Catterall, C. P. and Piper, S. D. (2005) Effects of edge habitat and nest characteristics on depredation of artificial nests in fragmented Australian tropical rainforest. Biodivers. Conserv. 14: 23312345.

Hurvich, C. M. and Tsai, C. L. (1989) Regression and time-series model selection in small samples. Biometrika 76: 297-307.

Imber, M., Harrison, M. and Harrison, J. (2000) Interactions between petrels, rats and rabbits on Whale Island, and effects of rat and rabbit eradication. New Zeal. J. Ecol. 24: 153-160.

Janzen, D. H. (1983) No park is an island increase in interference from outside as park size decreases. Oikos 41: 402-410.

Jones, H. P., Williamhenry, R., Howald, G. R., Tershy, B. R. and Croll, D. A. (2005) Pre- dation of artificial Xantus's murrelet (Synthliboramphus hypoleucus scrippsi) nests before and after black rat (Rattus rattus) eradication: Environ. Conserv. 32: 320-325.

Kenward, M. G. and Roger, J. H. (1997) Small sample inference for fixed effects from restricted maximum likelihood. Biometrics 53: 983-997.

King, D. I., Degraaf, R. M., Griffin, C. R. and Maier, T. J. (1999) Do predation rates on artificial nests accurately reflect predation rates on natural bird nests? J. Field Ornithol. 70: 257-262.

Lahti, D. C. (2001) The "edge effect on nest predation" hypothesis after twenty years. Biol. Conserv. 99: 365-374.

Larivière, S. (1999) Reasons why predators cannot be inferred from nest remains. Condor 101: 718-721.

Larivière, S. (2003) Edge effects, predator movements and the travel lane paradox. Wildl. Soc. Bull. 31: 315-320.

Laurance, W. F. (2005) The alteration of biotic interactions in fragmented tropical forests. Pp. $441-458$ in D. Burslem, M. Pinard and S. Hartley, eds. Biotic interactions in the tropics. Their role in the maintenance of species diversity. Cambridge, UK: Cambridge University Press.

Laurance, W. F., Lovejoy, T. E., Vasconcelos, H. L., Bruna, E. M., Didham, R. K., Stouffer, P. C., Gascon, C., Bierregaard, R. O., Laurance, S. G. and Sampaio, E. (2002) Ecosystem decay of Amazonian forest fragments: a 22 year investigation. Conserv. Biol. 16: 605-618.

Lewis, K. P. (2004) How important is the statistical approach for analyzing categorical data? A critique using artificial nests. Oikos 104: 305-315.

Maina, G. G. and Jackson, W. M. (2003) Effects of fragmentation on artificial nest predation in a tropical forest in Kenya. Biol. Conserv. 111: 161-169.

Malonza, K. (2001) A survey of the amphibians and reptiles of the Taita Hills. Pp. 91-96 in B. Bytebier, ed. Taita Hills biodiversity project report. Nairobi: National Museums of Kenya.

Martin, T. E., Scott, J. and Menge, C. (200o) Nest predation increases with parental activity: 
separating nest site and parental activity effects. Proc. R. Soc. B-Biol. Sci 267: 22872293.

Marzluff, J. M. and Ewing, K. (2001) Restoration of fragmented landscapes for the conservation of birds: a general framework and specific recommendations for urbanizing landscapes. Restor. Ecol. 9: 280-292.

Mazgajski, T. D. and Rejt, L. (2005) Forest fragment size affects edge effect in nest predation - experiment with artificial nests. Pol. J. Ecol. 53: 233-242.

Mittermeier, R. A., Gil, P. R., Hoffman, M., Pilgrim, J., Brooks, T., Mittermeier, C. G., Lamoreux, J. and da Fonseca, G. A. B. (2005) Hotspots revisited: earth's biologically richest and most endangered terrestrial ecoregions. Chicago: The University of Chicago Press.

Montgomerie, R. D. and Weatherhead, P. J. (1988) Risks and rewards of nest defense by parent birds. Q. Rev. Biol. 63: 167-187.

Morse, S. F. and Robinson, S. K. (1999) Nesting success of a neotropical migrant in a multiple-use forested landscape. Conserv. Biol. 13: 327-337.

Murcia, C. (1995) Edge effects in fragmented forests - implications for conservation. Trends Ecol. Evol 10: 58-62.

Ness, J. H. and Morin, D. F. (2008) Forest edges and landscape history shape interactions between plants, seed-dispersing ants and seed predators. Biol. Conserv. 141: 838-847.

Nour, N., Matthysen, E. and Dhondt, A. A. (1993) Artificial nest predation and habitat fragmentation: different trends in bird and mammal predators. Ecography 16: 111-116.

Oguge, N. O. (2001) Mammalogical research. Pp. $49-57$ in B. Bytebier, ed. Taita Hills biodiversity project report. Nairobi: National Museums of Kenya.

Pangau-Adam, M. Z., Waltert, M. and Muhlenberg, M. (2006) Nest predation risk on ground and shrub nests in forest margin areas of Sulawesi, Indonesia. Biodivers. Conserv. 15: 4143-4158.

Pärt, T. and Wretenberg, J. (2002) Do artificial nests reveal relative nest predation risk for real nests? J. Avian Biol. 33: 39-46.
Paton, P. W. C. (1994) The effect of edge on avian nest success - how strong is the evidence. Conserv. Biol. 8: 17-26.

Pimm, S. L. and Raven, P. (2000) Biodiversity extinction by numbers. Nature 403: 843-845.

Posa, M. R. C., Sodhi, N. S. and Koh, L. P. (2007) Predation on artificial nests and caterpillar models across a disturbance gradient in Subic Bay, Philippines. J. Trop. Ecol. 23: 27-33.

Robinson, W. D. and Robinson, T. R. (2001) Observations of predation events at bird nests in central Panama. J. Field Ornithol. 72: 43-48.

Robinson, W. D., Styrsky, J. N. and Brawn, J. D. (2005) Are artificial bird nests effective surrogates for estimating predation on real bird nests? A test with tropical birds. Auk 122: 843-852.

SAS Institute (2002-2003) SAS v. 9.1.3. Cary, North Carolina: SAS Institute.

SAS Institute (2008) SAS/STAT v. 9.2 User's Guide. Cary, North Carolina: SAS Institute.

Sekercioglu, C. H. (2006) Increasing awareness of avian ecological function. Trends Ecol. Evol. 21: 464-471.

Spanhove, T., Lehouck, V., Boets, P. and Lens, L. (2009) Forest fragmentation relaxes natural nest predation in an Afromontane forest. Animal Conservation. 12: In Press. DOI 10.1111/j.1469-1795.2009.00249.x

Stephens, S. E., Koons, D. N., Rotella, J. J. and Willey, D. W. (2003) Effects of habitat fragmentation on avian nesting success: a review of the evidence at multiple spatial scales. Biol. Conserv. 115: 101-110.

Telleria, J. L. and Diaz, M. (1995) Avian nest predation in a large natural gap of the Amazonian rain forest. J. Field Ornithol. 66: $343-351$.

Tewksbury, J. J., Garner, L., Garner, S., Lloyd, J. D., Saab, V. and Martin, T. E. (2006) Tests of landscape influence: nest predation and brood parasitism in fragmented ecosystems. Ecology 87: 759-768.

Tewksbury, J. J., Hejl, S. J. and Martin, T. E. (1998) Breeding productivity does not decline with increasing fragmentation in a western landscape. Ecology 79: 2890-2903. Weatherhead, P. J. and Blouin-Demers, G. (2004) Understanding avian nest predation: 
why ornithologists should study snakes. J. Avian Biol. 35: 185-190.

Weldon, A. J. and Haddad, N. M. (2005) The effects of patch shape on indigo buntings: evidence for an ecological trap. Ecology 86: 1422-1431.

Willebrand, T. and Marcström, V. (1988) On the danger of using dummy nests to study predation. Auk 105: 378-379.
Yasue, M. and Dearden, P. (2006) The effects of heat stress, predation risk and parental investment on Malaysian plover nest return times following a human disturbance. Biol. Conserv. 132: $472-480$.

Zanette, L. (2002) What do artificial nests tells us about nest predation? Biol. Conserv. 103: 323-329.

\section{TOON SPANHOVE*, VALÉRIE LEHOUCK}

Terrestrial Ecology Unit, Ghent University, K.L. Ledeganckstraat 35, 9000 Gent, Belgium and Ornithology Section, Zoology Department, National Museums of Kenya, PO Box 40658, oo1oo Nairobi, Kenya.

\section{LUC LENS}

Terrestrial Ecology Unit, Ghent University, K.L. Ledeganckstraat 35, 9000 Gent, Belgium.

${ }^{*}$ Author for correspondence; e-mail: toonspanhove@hotmail.com

Received 29 September 2008; revision accepted 29 January 2009 